\title{
Plasma plastin-3: A tumor marker in patients with non-small-cell lung cancer treated with nivolumab
}

\author{
KENGO KURIYAMA ${ }^{1}$, TAKEHIKO YOKOBORI ${ }^{2}$, MAKOTO SOHDA ${ }^{1}$, \\ NOBUHIRO NAKAZAWA ${ }^{1}$, TOSHIKI YAJIMA ${ }^{1,3}$, ICHIRO NARUSE ${ }^{4}$, HIROYUKI KUWANO $^{1}$, \\ KEN SHIRABE $^{1}$, KYOICHI KAIRA $^{5}$ and HIROSHI SAEKI ${ }^{1}$ \\ ${ }^{1}$ Department of General Surgical Science, Gunma University Graduate School of Medicine; \\ ${ }^{2}$ Division of Integrated Oncology Research, Gunma University Initiative for Advanced Research; \\ ${ }^{3}$ Department of Innovative Cancer Immunotherapy, Gunma University, Maebashi, Gunma 371-8511; \\ ${ }^{4}$ Division of Respiratory Medicine, Hidaka Hospital, Takasaki, Gunma 370-0001; ${ }^{5}$ Department of Respiration Medicine, \\ Saitama Medical University, International Medical Center, Hidaka, Saitama 350-1298, Japan
}

Received June 6, 2020; Accepted October 2, 2020

DOI: $10.3892 / \mathrm{ol} .2020 .12272$

\begin{abstract}
Plastin-3 (PLS3) is a circulating tumor cell marker associated with aggressive cancer phenotypes. The present study aimed to investigate the usability of plasma PLS3 concentration in assessing the diagnosis, prognosis and sensitivity to treatment in patients with non-small-cell lung cancer (NSCLC) treated with nivolumab. A total of 33 patients with recurrent or advanced NSCLC were treated with nivolumab, and 10 healthy volunteers were retrospectively enrolled. Plasma concentrations of PLS3 were determined by ELISA. Plasma PLS3 concentration in patients with NSCLC was significantly higher compared with that in healthy volunteers (median $7.64 \mathrm{ng} / \mathrm{ml}$ vs. $3.13 \mathrm{ng} / \mathrm{ml}, \mathrm{P}<0.001$ ). Univariate analysis indicated that PLS3 $\leq 5.43 \mathrm{ng} / \mathrm{ml}$ was a predictor of partial response. Patients with PLS3 $>8.55 \mathrm{ng} / \mathrm{ml}$ exhibited a poorer prognosis compared with those in the PLS3 $\leq 8.55 \mathrm{ng} / \mathrm{ml}$
\end{abstract}

Correspondence to: Dr Takehiko Yokobori, Division of Integrated Oncology Research, Gunma University Initiative for Advanced Research, 3-39-22 Showa-machi, Maebashi, Gunma 371-8511, Japan E-mail: bori45@gunma-u.ac.jp

Dr Makoto Sohda, Department of General Surgical Science, Gunma University Graduate School of Medicine, 3-39-22 Showa-machi, Maebashi, Gunma 371-8511, Japan

E-mail:msohda@gunma-u.ac.jp

Abbreviations: PLS3, plastin-3; NSCLC, non-small-cell lung cancer; ICI, immune checkpoint inhibitor; PD-L1, programmed death ligand-1; MHC, major histocompatibility complex; EMT, epithelial-mesenchymal transition; CTCs, circulating tumor cells; PR, partial response; SD, stable disease; PD, progressive disease; Foxp3, forkhead box protein P3; ROC, receiver operating characteristic

Key words: lung cancer, plastin-3, tumor marker, nivolumab, ICI resistance group. A high plasma PLS3 concentration was a predictor of poor overall survival. In conclusion, plasma PLS3 concentration was identified as a marker for the diagnosis, treatment sensitivity and prognosis in patients with NSCLC treated with nivolumab. Plasma PLS3 may be a clinically useful tumor marker in patients with NSCLC; future prospective studies may confirm these results and explore its use in other cancers.

\section{Introduction}

Lung cancer is one of the leading causes of cancer-related deaths globally, 1.8 million deaths occurred in 2018, representing close to 1 in 5 (18.4\%) cancer deaths (1). Non-small-cell lung cancer (NSCLC) accounts for $80-90 \%$ of lung cancer cases (2). Surgical treatment is recommended for patients with early-stage lung cancer, whereas chemotherapy is preferred in patients with advanced or recurrent disease $(3,4)$. Although multimodal therapy for NSCLC has exhibited progress in recent years, the overall 5-year survival rate for advanced NSCLC is only $4 \%(1,5)$. Previous studies have demonstrated the treatment efficacy of an immune checkpoint inhibitor (ICI), nivolumab, developed as an anti-programmed death-1 (PD-1) antibody, for patients previously treated with one platinum-containing regimen for NSCLC $(6,7)$. Although ICIs such as nivolumab or pembrolizumab serve a key role in systemic therapy for advanced NSCLC, almost all non-responder patients receive no therapeutic benefits from expensive ICIs, accompanied by immune-related adverse events (8). Kurman and Murgu (9) have reported accelerating disease progression following the administration of ICIs in patients with advanced NSCLC, referred to as hyper-progressive disease. Therefore, established biomarkers to estimate the sensitivity to ICIs are needed. A number of studies have reported on useful biomarkers for predicting sensitivity to ICIs, including programmed death ligand-1 (PD-L1) expression in tumor tissues, tumor mutation burden and interferon- $\gamma$ (IFN- $\gamma$ ) signature (10-12). However, evaluating these factors requires sufficient tumor tissues obtained through invasive procedures. Therefore, novel, less 
invasive diagnostic tools that can predict the sensitivity to ICIs are necessary.

The mechanisms of resistance to ICIs have attracted attention from oncologists to improve treatment efficacy. One of the most validated and characterized mechanisms is the downregulation of antigen presentation. Genetic alterations in $\beta$-2-microglobulin, an essential component of the major histocompatibility complex (MHC) class I antigen presentation, have been identified in progressing lesions in patients who exhibited an initial response to PD-1 blockade (13). Loss of human leukocyte antigen genes has been observed in patients with NSCLC, resulting in a loss of MHC class I presentation, which is associated with resistance to ICI (14). Recruitment and activation of immune-suppressive cells, including myeloid-derived suppressor cells, and regulatory $\mathrm{T}$ cells also induce resistance to ICIs $(15,16)$. Epithelial-mesenchymal transition (EMT) is another mechanism of resistance to ICIs and is an important regulatory mechanism of cancer invasion, metastasis, therapeutic resistance and poor prognosis (17). EMT directly induces the expression of PD-L1 and other checkpoint molecules that inhibit T cell-mediated cytotoxicity against cancer cells $(18,19)$. Tumor cells undergoing EMT also express immune-suppressive cytokines, such as transforming growth factor (TGF)- $\beta$, and enhanced recruitment of immune-suppressive cells (20). Therefore, EMT is considered to be a resistance factor to ICIs and a target mechanism that may improve the efficacy of ICIs.

Plastin-3 (PLS3) encodes an actin-bundling protein that facilitates cofilin-mediated polymerization of actin fibers $(21,22)$. PLS3 is associated with EMT-induced aggressive phenotypes and is expressed in whole solid cancers, but is not present in circulation, including whole blood cells (23). However, in the aforementioned study, PLS3 expression was identified as a novel marker for circulating tumor cells (CTCs) with EMT phenotypes in colorectal cancer, and the results demonstrated the usability of PLS3 detection in peripheral blood as a marker for EMT-induced CTCs and poor prognosis using PCR-based analyses (23). By contrast, the clinical significance of PLS3 protein concentration in the peripheral blood measured using ELISA, which is one of the most popular diagnostic tools in the clinic, has not been determined. In addition, whether PLS3 detection in blood samples may be associated with sensitivity to nivolumab treatment and prognosis in patients with NSCLC remains unknown.

The aim of the present study was to determine the usability of plasma PLS3 protein levels as a tumor marker of NSCLC and a predictive marker of sensitivity to nivolumab treatment.

\section{Materials and methods}

Patients. For ELISA analysis, a total of 33 patients with recurrent or advanced NSCLC who were treated with nivolumab at Gunma University Hospital (Maebashi, Japan) and Hidaka Hospital (Takasaki, Japan) between February 2016 and February 2017 were included in this retrospective study. The mean age was 66.4 years (age range, $47-82$ years); 25 patients were male and 8 were female. The inclusion criteria were as follows: i) Pathologically diagnosed NSCLC; ii) recurrent or advanced NSCLC; iii) candidates for nivolumab treatment after initial chemotherapy; and iv) performance status based on the Eastern Cooperative Oncology Group guidelines corresponding to $0-2$. Blood samples and medical records of patients included in a previous study (24) were evaluated. Response Evaluation Criteria In Solid Tumors (RECIST) version 1.1 was used to discriminate between partial response (PR) and stable disease (SD) or progressive disease (PD) (25). The follow-up duration for censored cases ranged between 2.9 and 50.7 months (median, 15.8 months). The patients provided written informed consent. The present study conformed to the Declaration of Helsinki and was approved by the Institutional Review Board for Clinical Research at the Gunma University Hospital (approval no. 1404) and Hidaka Hospital (approval no. 124). For PLS3 immunohistostaining, a total of 34 patients including five patients in the aforementioned cohort and another 29 patients with NSCLC who underwent surgical resection at Gunma University Hospital between January 2001 and December 2007 were included. The study of these 29 patients was also approved by the Institutional Review Board for Clinical Research at the Gunma University Hospital (approval no. 150044), and patient consent was obtained using the opt-out method. The mean age was 66.4 years (age range, 45-84 years); 20 patients were male and 14 were female.

ELISA. Peripheral blood was collected from each patient with NSCLC before treatment with nivolumab. Plasma was obtained by centrifugation at $1,689 \mathrm{x} \mathrm{g}$ for $10 \mathrm{~min}$ at room temperature and stored at $-80^{\circ} \mathrm{C}$. Plasma concentrations of PLS3 were determined using a Human Plastin 3 (PLS3) ELISA kit (cat. no. MBS4503796; MyBioSource, Inc.) ELISA according to the manufacturer's instructions. In addition, 10 anonymized plasma samples collected from healthy volunteers were used. All healthy volunteers provided informed consent, and the use of blood samples obtained from healthy volunteers was approved by the Institutional Review Board for Clinical Research at the Gunma University Hospital (approval no. HS2019-271). All samples were examined in duplicate. The dose-response curves for standards were obtained by 4-parameter curve fitting using SkanIt Software 4.1 for Microplate Readers (Thermo Fisher Scientific, Inc.).

Immunohistochemistry. Immunohistostaining of PLS3 was performed using surgically resected lung cancer specimens to evaluate the expression levels of PLS3 in lung cancer tissues. In total, tissues from 34 patients ( 27 with adenocarcinoma and 7 with squamous cell carcinoma) were evaluated for PLS3 expression using immunohistochemistry. Subsequently, immunohistostaining of PD-L1, CD8, and forkhead box protein P3 (Foxp3) was performed in the ELISA cohort. Among 33 patients in the ELISA cohort, serial sections consisting of the resected specimens $(n=14)$ and needle biopsies $(n=8)$ from patients with NSCLC were assessed for the expression of PD-L1 and CD8, only for those cases in whom we could obtain the clinical samples. For Foxp3 staining, 21 available samples in the ELISA cohort were evaluated. For immunohistochemistry, 4- $\mu \mathrm{m}$ sections were cut from the paraffin blocks of each sample. Each section was mounted on a silane-coated glass slide, deparaffinized in xylene, rehydrated in $100 \%$ ethanol and incubated for $30 \mathrm{~min}$ at room temperature in $0.3 \%$ hydrogen peroxide to block endogenous peroxidase activity. After rehydration through a graded series of the ethanol treatments $(90 \%$ for 
$1 \mathrm{~min}, 80 \%$ for $1 \mathrm{~min}$, and $60 \%$ for $1 \mathrm{~min}$ ), the sections for PLS3 staining were subjected to antigen retrieval by heating in citrate buffer ( $\mathrm{pH} 6.0)$ at $120^{\circ} \mathrm{C}$ for $20 \mathrm{~min}$ in an autoclave. The sections for CD8 and Foxp3 staining were heated in boiling water using Immunosaver (Nisshin EM Co., Ltd.) for $45 \mathrm{~min}$ at 98- $100^{\circ} \mathrm{C}$ for antigen retrieval. For PD-L1 staining, Universal HIER antigen retrieval reagent (cat. no. ab208572; Abcam) was used at $120^{\circ} \mathrm{C}$ for $20 \mathrm{~min}$ in an autoclave. Non-specific binding sites were blocked by incubating the sections with Protein Block Serum-Free (Dako; Agilent Technologies, Inc.) for $30 \mathrm{~min}$ at room temperature. The samples were incubated overnight at $4{ }^{\circ} \mathrm{C}$ with the following primary antibodies: PLS3 (cat. no. sc-166208; 1:200; Santa Cruz Biotechnology, Inc.), PD-L1 (E1L3N Rabbit mAb 1:200; cat. no. 13684; Cell signaling Technology, Inc.), CD8 (cat. no. ab4055; 1:1,000; Abcam) and Foxp3 (cat. no. ab20034; 1:200; Abcam). The primary antibody was visualized by the Histofine Simple Stain MAX-PO (Multi) Kit (Nichirei Biosciences, Inc.). Chromogen 3,3-diaminobenzidine tetrahydrochloride was used as a $0.02 \%$ solution in $50 \mathrm{mM}$ ammonium acetate-citrate acid buffer ( $\mathrm{pH} 6.0$ ) containing $0.005 \%$ hydrogen peroxide. The sections were lightly counterstained with hematoxylin and mounted.

The tissue sections were examined by two independent evaluators who were blinded to the patient data. For evaluation of the PLS3 expression, the staining intensity was scored as follows: 0 , none; 1 , weak; 2 , moderate; or 3, strong. Scores 1-3 were defined as positive PLS3 expression. The expression of PD-L1 was evaluated using a semiquantitative scoring method according to the percentage of stained cells: $1, \leq 1 ; 2,1-5$; $3,5-10 ; 4,10-50$; and $5, \geq 50 \%$. Tumors with a score $>3$ were graded as positive. CD8 and Foxp3 were semi-quantitatively evaluated based on the extent of positive lymphocytes infiltrating the tumor specimens, and patients with $>5 \%$ positive lymphocytes were defined as positive for CD8 and Foxp3 based on a previous study $(24,26)$.

Statistical analysis. The data were presented as the mean \pm standard deviation or median and the interquartile range (IQR). Statistical analyses were performed using the Mann-Whitney $U$ test for continuous variables and the $\chi^{2}$ test for categorical variables. Kaplan-Meier curves were generated for overall survival, and statistical significance was examined using the log-rank test. Univariate analyses were performed using logistic regression analysis or Cox's proportional hazards model. Receiver operating characteristic (ROC) curve analyses were used to evaluate the potential of plasma PLS3 concentration as a cancer diagnostic marker, predictor of sensitivity to nivolumab and a marker of poor prognosis. All statistical analyses were performed using JMP software (SAS Institute, Inc.). A two-tailed $\mathrm{P}<0.05$ was considered to indicate a statistically significant difference.

\section{Results}

Immunohistochemistry of PLS3 expression. Prior to the ELISA analyses, immunohistochemical analysis of PLS3 expression was performed using 34 surgically resected NSCLC specimens to evaluate the expression levels of PLS3 in lung cancer tissues. Fig. S1 demonstrates the representative
Table I. Association between plasma PLS3 concentration and sensitivity to nivolumab treatment.

\begin{tabular}{lccc}
\hline Group & PR $(\mathrm{n}=11)$ & $\mathrm{SD}+\mathrm{PD}(\mathrm{n}=22)$ & P-value \\
\hline PLS3 $\leq 5.43 \mathrm{ng} / \mathrm{ml}$ & 4 & 1 & $0.016^{\mathrm{a}}$ \\
PLS3 $>5.43 \mathrm{ng} / \mathrm{ml}$ & 7 & 21 & \\
\hline
\end{tabular}

${ }^{a} \mathrm{P}<0.05$. PLS3, plastin 3; PR, partial response; $\mathrm{SD}+\mathrm{PD}$, stable or progressive disease.

immunohistochemical staining of PLS3 in negative (Fig. S1A) and positive (Fig. S1B) cases. The expression of the PLS3 protein was predominantly observed in the cytoplasm. The rate of positive PLS3 expression was $88.2 \%$ (31/34 patients).

Plasma PLS3 levels as a diagnostic marker of cancer. In total, 10 healthy volunteers ( 8 male and 2 female) and 33 patients with recurrent or advanced NSCLC were enrolled in the present study. The mean age of the healthy volunteers and patients with NSCLC was $33.7 \pm 3.6$ and $66.4 \pm 9.1$ years, respectively $(\mathrm{P}<0.001)$. Plasma PLS3 concentrations in healthy volunteers and patients with NSCLC are presented in Fig. 1. The median plasma PLS3 concentration was significantly higher in patients with NSCLC compared with that in healthy volunteers (median $7.64 \mathrm{ng} / \mathrm{ml}$ vs. $3.13 \mathrm{ng} / \mathrm{ml}, \mathrm{P}<0.001)$. The diagnostic value of plasma PLS3 concentration to discriminate between patients with NSCLC and healthy volunteers was next determined. ROC analysis for plasma PLS3 concentration revealed that the optimal cut-off value for patients with NSCLC was $5.18 \mathrm{ng} / \mathrm{ml}$ [area under the curve (AUC), 0.952; sensitivity, 97.0\%; specificity, 90.0\%; Fig. 2A). Using this cut-off value, 31 patients with NSCLC (93.9\%) had PLS3 >5.18 ng/ml (Fig. 2B). The positivity rate of PLS3 in all patients with NSCLC was higher compared with that of CEA in patients with adenocarcinoma $(66.6 \%)$ or SCC antigen in patients with squamous cell carcinoma $(40 \%)$.

Plasma PLS3 levels and sensitivity to nivolumab treatment. The association between plasma PLS3 concentration and the sensitivity to nivolumab treatment was analyzed in patients with NSCLC. Fig. 3 demonstrates the results of the ROC analysis of plasma PLS3 concentration to discriminate between PR and SD or PD according to the RECIST. The optimal cut-off value for PR was $5.43 \mathrm{ng} / \mathrm{ml}$ (AUC, 0.607; sensitivity, 36.4\%; specificity, 95.4\%). Using this cut-off value, the rate of PR in the PLS3 $\leq 5.43 \mathrm{ng} / \mathrm{ml}$ group was significantly higher compared with that in the PLS3 $>5.43 \mathrm{ng} / \mathrm{ml}$ group $(\mathrm{P}=0.016$; Table I). In addition, seven variables, including tumoral PD-L1, CD8 and PLS3 concentration, were evaluated as potential predictive factors of PR; however, univariate analysis indicated that PLS3 $\leq 5.43 \mathrm{ng} / \mathrm{ml}$ was the sole predictor of PR (odds ratio, 0.08; 95\% $\mathrm{CI}, 0.01-0.68 ; \mathrm{P}=0.019$; Table II).

Plasma PLS3 levels and overall survival. The prognostic value of the plasma PLS3 concentration was evaluated in patients with NSCLC treated with nivolumab. ROC analysis of plasma PLS3 concentration revealed that the optimal 


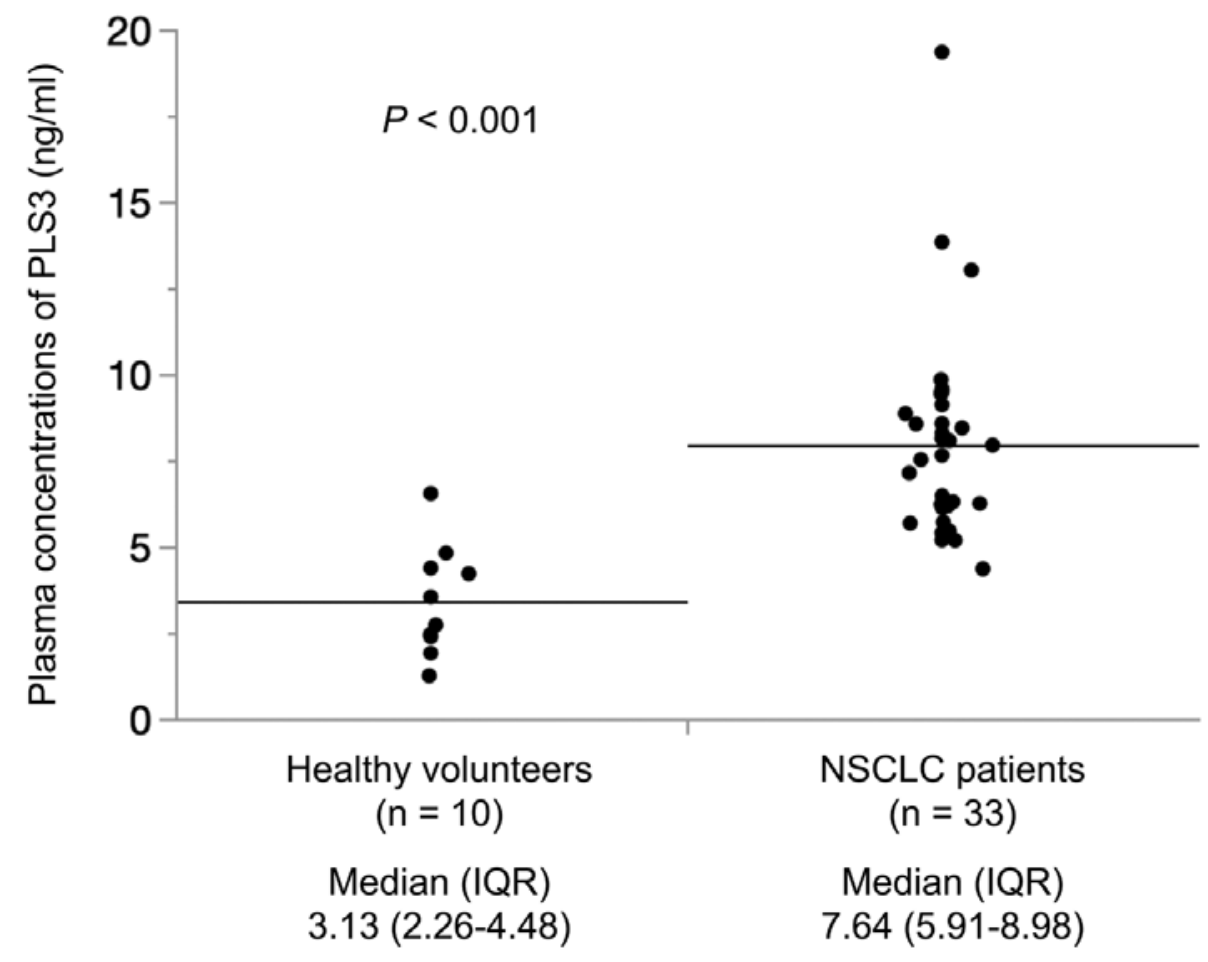

Figure 1. Comparison of plasma PLS3 concentrations between healthy volunteers and patients with NSCLC. Horizontal lines indicate the mean plasma PLS3 concentration. PLS3, plastin 3; NSCLC, non-small cell lung cancer; IQR, interquartile range.

A NSCLC patients / healthy volunteers
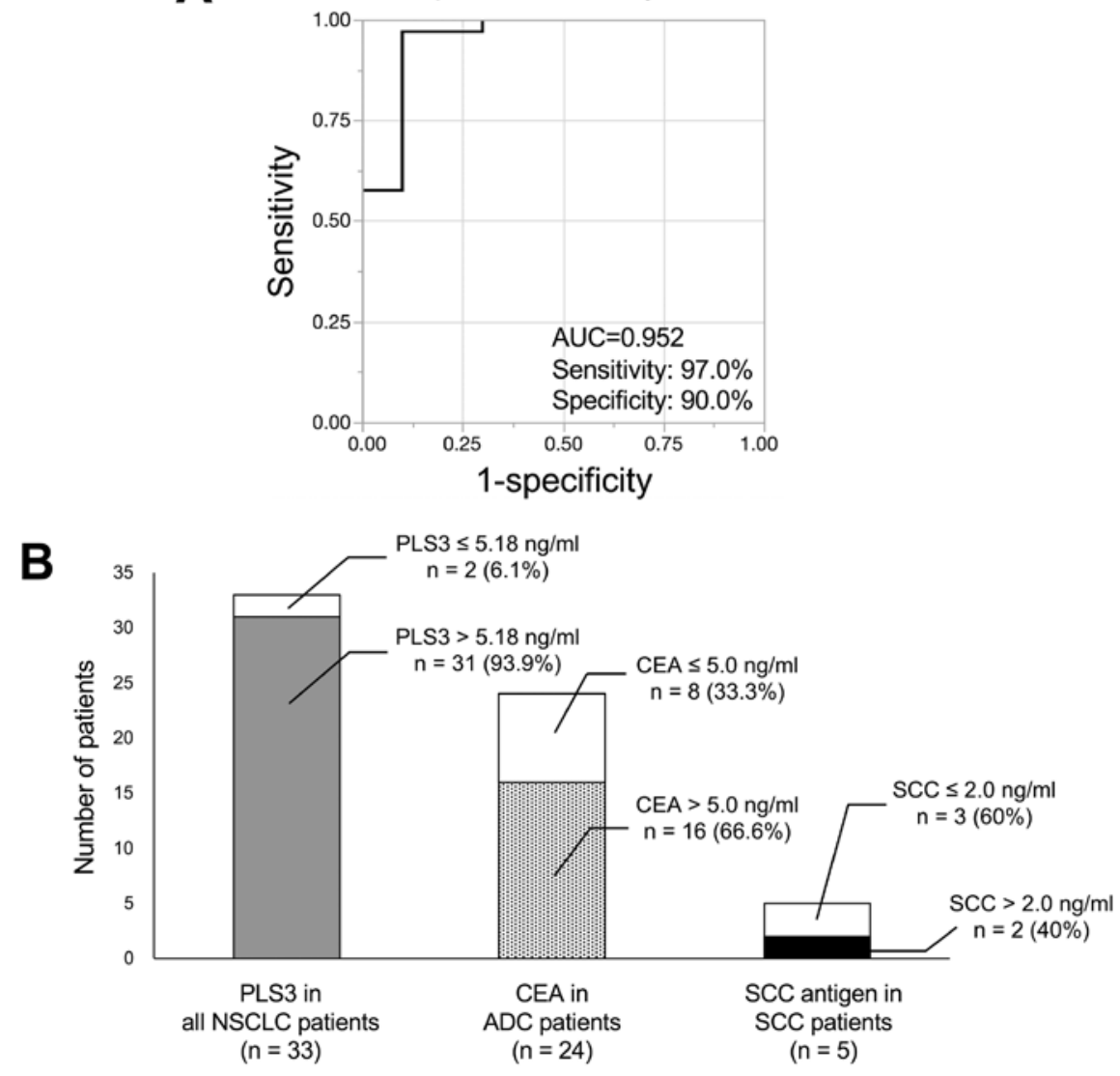

Figure 2. Diagnostic value of plasma PLS3 concentration as a tumor marker in patients with NSCLC. (A) ROC analysis for the ability of the plasma PLS3 concentration to discriminate between patients with NSCLC and healthy volunteers. (B) Left stacked column chart showed the number of patients with plasma PLS3 $>5.18$ and $\leq 5.18 \mathrm{ng} / \mathrm{ml}$ among all patients with NSCLC. Middle stacked column chart presented the number of CEA $\leq 5.0$ and $>5.0 \mathrm{ng} / \mathrm{ml}$ in patients with lung ADC. Right stacked column chart indicates the number of SCC antigen $\leq 2.0$ and $>2.0 \mathrm{ng} / \mathrm{ml}$ in patients with lung SCC. PLS3, plastin 3; NSCLC, non-small cell lung cancer; ROC, receiver operating characteristic; AUC, area under the curve; ADC, adenocarcinoma; SCC, squamous cell carcinoma. 
Table II. Univariate analysis of the predictors associated with nivolumab treatment efficacy.

\begin{tabular}{llcr}
\hline & \multicolumn{3}{c}{ Univariate analysis } \\
\cline { 2 - 4 } Clinicopathological characteristic & OR & $95 \%$ CI & P-value \\
\hline Age, years ( $\leq 65$ vs. $>65)$ & 1.46 & $0.34-6.95$ & 0.617 \\
Sex (male vs. female) & 0.21 & $0.01-1.48$ & 0.127 \\
Histology (ADC vs. SCC) & 0.76 & $0.09-4.34$ & 0.761 \\
PD-L1 expression (negative vs. positive) & 1.25 & $0.21-8.13$ & 0.805 \\
CD8 expression (negative vs. positive) & 2.55 & $0.29-55.41$ & 0.417 \\
Recurrent disease (no vs. yes) & 0.69 & $0.15-3.06$ & 0.616 \\
Plasma PLS3 concentration, ng/ml ( $\leq 5.43$ vs. $>5.43)$ & 0.08 & $0.01-0.68$ & $0.019^{\text {a }}$ \\
\hline
\end{tabular}

${ }^{\text {a }}<$ 0 .05. OR, odds ratio; CI, confidence interval; ADC, adenocarcinoma; SCC, squamous cell carcinoma; PD-L1, programmed death ligand 1; PLS3, plastin 3.

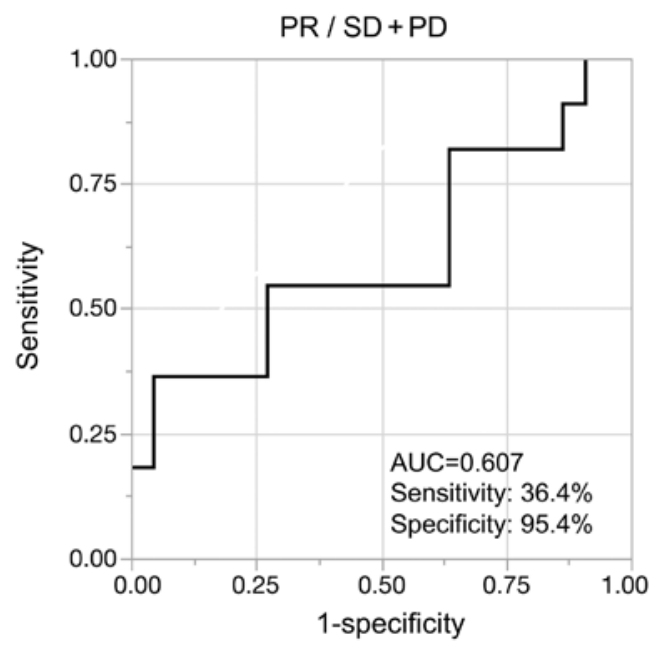

Figure 3. ROC curve analysis of plasma PLS3 concentration as a predictor of sensitivity to nivolumab in patients with NSCLC. ROC analysis for plasma PLS3 concentration to discriminate between PR and SD + PD by RECIST is presented. ROC, receiver operating characteristic; PLS3, plastin 3; NSCLC, non-small cell lung cancer; PR, partial response; $\mathrm{SD}+\mathrm{PD}$, stable or progressive disease; RECIST, response evaluation criteria in solid tumors; AUC, area under the curve.

cut-off value for mortality was $8.55 \mathrm{ng} / \mathrm{ml}$ (AUC,0.609; sensitivity, $90.0 \%$; specificity, $39.1 \%$; Fig. 4A). The patients were divided into PLS3 $\leq 8.55$ and $>8.55 \mathrm{ng} / \mathrm{ml}$ groups according to this cut-off point. The associations between clinicopathological characteristics and PLS3 concentration in patients with NSCLC are presented in Table III; no significant differences in clinicopathological characteristics were identified between the PLS3 $\leq 8.55$ and $>8.55 \mathrm{ng} / \mathrm{ml}$ groups. The prognostic analysis of patients with NSCLC according to PLS3 concentration demonstrated that the patients in the PLS3 $>8.55 \mathrm{ng} / \mathrm{ml}$ group exhibited a poorer prognosis compared with those in the PLS3 $\leq 8.55 \mathrm{ng} / \mathrm{ml}$ group (Fig. 4B). Univariate analysis revealed that the high plasma PLS3 concentration was the sole predictor of poor survival (hazard ratio, 2.40; 95\% CI, 1.01-5.67; $\mathrm{P}=0.047$; Table IV). The prognostic values of the other two cut-off point $(5.18 \mathrm{ng} / \mathrm{ml}$ used for diagnosis and $5.43 \mathrm{ng} / \mathrm{ml}$ used for treatment sensitivity) are presented in Fig. S2. Using the cut-off values of 5.18 and $5.43 \mathrm{ng} / \mathrm{ml}$, no significant differences were observed in patient overall survival rates according to the PLS3 concentration ( $\mathrm{P}=0.214$ and 0.306 , respectively).

\section{Discussion}

The clinical usability of plasma PLS3 in patients with NSCLC remains unknown. In addition, the identification of novel, less invasive diagnostic tools that can predict the sensitivity to ICIs are necessary. The present study first demonstrated that the plasma PLS3 concentration in patients with NSCLC was significantly higher compared with that in healthy volunteers. In addition, low PLS3 concentration was associated with PR according to the RECIST in patients with NSCLC treated with nivolumab, with a cut-off value of $5.43 \mathrm{ng} / \mathrm{ml}$. PLS3 concentration $\geq 8.55 \mathrm{ng} / \mathrm{ml}$ was the sole predictor of poor overall survival. To the best of our knowledge, the present study is the first to indicate the clinical significance of plasma PLS3 concentration in the prediction of the diagnosis, prognosis and sensitivity to nivolumab treatment in patients with NSCLC. Furthermore, the present study is unique due to the use of ELISA to measure peripheral PLS3 protein concentration in the plasma, which may enhance its clinical utility.

Tumor markers are broadly used in screening, diagnosis, monitoring and predicting therapeutic response and prognosis in various types of cancer, such as CEA or SCC antigen in NSCLC (27-30). Ideally, it is desirable that tumor markers are detected only in patients with cancer and not in healthy individuals. The present study focused on EMT-related characteristics and unique expression profiles of PLS3 to examine its potential as a novel tumor marker in the blood. Our previous study validated the PLS3 expression profiles in several cancer cell lines, including hematopoietic malignancies; as a result, the PLS3 expression was detected in solid cancer cell lines including esophageal cancer, gastric cancer, liver tumor, pancreatic cancer, breast cancer, lung cancer, prostate cancer and melanoma, but not in hematopoietic malignancies or blood samples from healthy individuals (23). The results of the present study demonstrated that plasma PLS3 protein concentration in patients with NSCLC was significantly higher compared with that in healthy volunteers. Further studies are 
Table III. Associations between clinicopathological characteristics and plasma PLS3 concentrations in patients with non-small cell lung cancer treated with nivolumab.

\begin{tabular}{|c|c|c|c|}
\hline Clinicopathological characteristic & $\mathrm{PLS} 3 \leq 8.55 \mathrm{ng} / \mathrm{ml}(\mathrm{n}=23)$ & PLS3 $>8.55 \mathrm{ng} / \mathrm{ml}(\mathrm{n}=10)$ & P-value \\
\hline Age, years, mean \pm SD & $67.3 \pm 8.6$ & $64.2 \pm 10.3$ & 0.377 \\
\hline \multicolumn{4}{|l|}{ Sex } \\
\hline Male & 18 & 7 & \multirow[t]{2}{*}{0.612} \\
\hline Female & 5 & 3 & \\
\hline \multicolumn{4}{|l|}{ Histology } \\
\hline SCC & 6 & 1 & \multirow[t]{2}{*}{0.299} \\
\hline $\mathrm{ADC}$ & 17 & 9 & \\
\hline \multicolumn{4}{|l|}{ PD-L1 } \\
\hline Negative & 5 & 4 & \multirow[t]{2}{*}{0.512} \\
\hline Positive & 9 & 4 & \\
\hline \multicolumn{4}{|l|}{$\mathrm{CD} 8$} \\
\hline Negative & 2 & 3 & \multirow[t]{2}{*}{0.211} \\
\hline Positive & 12 & 5 & \\
\hline \multicolumn{4}{|l|}{ Foxp3 } \\
\hline Negative & 2 & 4 & \multirow[t]{2}{*}{0.163} \\
\hline Positive & 10 & 5 & \\
\hline \multicolumn{4}{|l|}{ Driver mutation } \\
\hline EGFR & 2 & 1 & \multirow[t]{4}{*}{0.364} \\
\hline ALK & 0 & 1 & \\
\hline Wild-type & 15 & 7 & \\
\hline Unknown & 6 & 1 & \\
\hline \multicolumn{4}{|l|}{ Recurrent disease } \\
\hline No & 8 & 5 & \multirow[t]{2}{*}{0.411} \\
\hline Yes & 15 & 5 & \\
\hline Number of previous regimens, mean \pm SD & $2.7 \pm 2.3$ & $3.2 \pm 1.9$ & 0.419 \\
\hline Nivolumab administrations, mean \pm SD & $17.5 \pm 20.4$ & $9.2 \pm 10.1$ & 0.215 \\
\hline \multicolumn{4}{|l|}{ irAE } \\
\hline Negative & 19 & 7 & \multirow[t]{2}{*}{0.416} \\
\hline Positive & 4 & 3 & \\
\hline \multicolumn{4}{|l|}{ Therapeutic effect } \\
\hline PR & 9 & 2 & \multirow[t]{2}{*}{0.284} \\
\hline $\mathrm{SD}+\mathrm{PD}$ & 14 & 8 & \\
\hline \multicolumn{4}{|l|}{ Reason for treatment discontinuation } \\
\hline Disease progression & 15 & 7 & \multirow[t]{6}{*}{0.448} \\
\hline irAE & 3 & 0 & \\
\hline Decreased PS & 3 & 0 & \\
\hline Death due to AMI & 0 & 1 & \\
\hline Long stable disease & 1 & 0 & \\
\hline Treatment continuation & 1 & 0 & \\
\hline
\end{tabular}

PLS3, plastin 3; SCC, squamous cell carcinoma; ADC, adenocarcinoma; PD-L1, programmed death ligand 1; Foxp3, forkhead box protein P3; EGFR, epidermal growth factor receptor; ALK, anaplastic lymphoma kinase; irAE, immune-related adverse events; PR, partial response; $\mathrm{SD}+\mathrm{PD}$, stable or progressive disease; PS, performance status; AMI, acute myocardial infarction.

warranted to clarify the clinical significance of plasma PLS3 as a diagnostic marker in a broad range of solid tumors.

Various studies have reported the predictive value of ICI sensitivity markers, such as tumoral PD-L1 expression (10), tumor mutation burden (11) and IFN- $\gamma$ gene signature (12); however, for predicting the sensitivity to nivolumab, established biomarkers that are obtained via less invasive techniques are urgently needed. Recent studies have reported that cancer cells undergoing EMT were resistant to immunotherapy $(20,31)$. In addition, Dodagatta-Marri et al (32) 
Table IV. Univariate analysis of clinicopathological factors affecting overall survival.

\begin{tabular}{|c|c|c|c|}
\hline \multirow[b]{2}{*}{ Clinicopathological characteristics } & \multicolumn{3}{|c|}{ Univariate analysis } \\
\hline & HR & $95 \% \mathrm{CI}$ & P-value \\
\hline Age, years $(\leq 65$ vs. $>65)$ & 0.60 & $0.26-1.37$ & 0.224 \\
\hline Sex (male vs. female) & 2.07 & $0.81-5.27$ & 0.128 \\
\hline Histology (ADC vs. SCC) & 1.58 & $0.57-4.38$ & 0.380 \\
\hline PD-L1 expression (negative vs. positive) & 0.72 & $0.26-2.02$ & 0.535 \\
\hline CD8 expression (negative vs. positive) & 0.74 & $0.24-2.30$ & 0.602 \\
\hline Recurrent disease (no vs. yes) & 0.77 & $0.34-1.77$ & 0.539 \\
\hline Plasma PLS3 concentration, $\mathrm{ng} / \mathrm{ml}(\leq 8.55$ vs. $>8.55)$ & 2.40 & $1.01-5.67$ & $0.047^{\mathrm{a}}$ \\
\hline
\end{tabular}

${ }^{a} \mathrm{P}<0.05$. HR, hazard ratio; CI, confidence interval; ADC, adenocarcinoma; SCC, squamous cell carcinoma; PD-L1, programmed death ligand 1; PLS3, plastin 3.

A

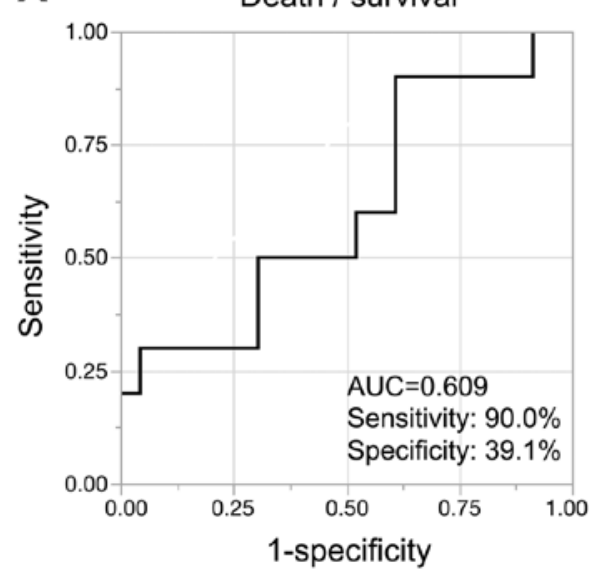

B

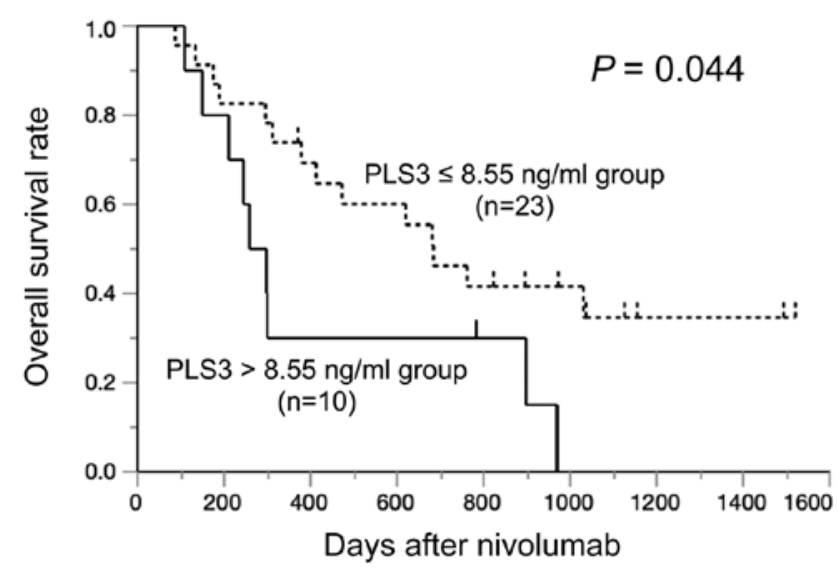

Figure 4. Plasma PLS3 concentration and overall survival in patients with NSCLC treated with nivolumab. (A) ROC analysis for the ability of plasma PLS3 concentration to predict overall survival. (B) Overall survival curves of patients with NSCLC according to plasma PLS3 concentration. PLS3, plastin 3; NSCLC, non-small cell lung cancer; ROC, receiver operating characteristic; AUC, area under the curve.

have demonstrated that the combination of anti-PD-1 and anti-TGF- $\beta$ antibodies inhibit the EMT signaling pathways in murine tumor models. Furthermore, PLS3 induces the EMT via the TGF- $\beta$ signaling pathway, and PLS3 expression is also detectable in the EMT-induced CTCs $(33,34)$. In the present study, plasma PLS3, but not tumoral PD-L1, expression was associated with sensitivity to nivolumab treatment, although the origin of plasma PLS3 (EMT-induced CTCs, tumor mass or other tissue) was unclear. A previous study has reported that EMT causes therapeutic resistance to not only nivolumab, but also other immunotherapies (20). Therefore, the evaluation of plasma PLS3 may also be a useful predictive marker of sensitivity to treatment with a range of ICIs, including anti-cytotoxic T lymphocyte-associated protein 4 and anti-PD-L1 antibodies.

As aforementioned, EMT promotes tumor invasion, metastasis, therapeutic resistance and poor prognosis, and PLS3 has been reported as one of the regulators of EMT $(17,23)$. Our previous study demonstrated by PCR detection that the mRNA levels of $P L S 3$ in the tumor tissue were associated with cancer progression and a poor prognosis in patients with colorectal cancer (23). In addition, Ueo et al (34) have demonstrated that PLS3 evaluation in the peripheral blood by PCR-based analysis is associated with a poor prognosis in patients with breast cancer. However, whether the protein expression level of PLS3 in blood samples using ELISA may predict therapeutic response and cancer prognosis remained unknown. The results of the present study demonstrated that the high plasma PLS3 concentration was associated with nivolumab resistance and poor survival. PCR-based gene expression analysis in the peripheral blood may require complicated methods to extract the unstable total RNA from blood samples. By contrast, ELISA-based analysis requires serum or plasma samples obtained by standard collection tubes frequently used in clinical practice. The evaluation of plasma PLS3 by ELISA may be easier to use in clinical application compared with gene expression-based analysis.

The present study had several limitations. First, a retrospective design was used, and a small sample size was included. Second, the mean age of healthy volunteers was different compared with that of patients with NSCLC, which may have affected the plasma PLS3 concentration among individuals. Third, there is the possibility of false-positive 
cases, as plasma PLS3 may originate from not only CTCs or primary tumors, but also healthy solid tissues of the whole body. Fourth, only patients with recurrent or advanced NSCLC who possessed large numbers of cancer cells were enrolled; therefore, further studies in patients with early-stage cancer who may possess relatively small numbers of cancer cells are warranted to determine whether plasma PLS3 may be useful as a diagnostic marker for cancer. Fifth, all patients in the present study had history of previous chemotherapy treatment. In Japan, nivolumab has been covered by the medical insurance system for NSCLC as second-line therapy since December 2015, and at present, a number of ICIs are available as first-line therapy (4). The present study did not include untreated patients with NSCLC; therefore, it remains unclear whether plasma PLS3 may predict the sensitivity to nivolumab treatment or prognosis as first-line therapy. Sixth, the present study did not include functional experiments on the relationship between plasma PLS3 expression and nivolumab using in vitro or in vivo analyses.

In conclusion, the results of the present study demonstrated the diagnostic value of plasma PLS3 concentration in distinguishing patients with NSCLC from healthy volunteers. In addition, the low pretreatment plasma PLS3 concentration was associated with high responsiveness to nivolumab treatment, whereas high plasma PLS3 concentration predicted poor overall survival in patients with NSCLC treated with nivolumab. These observations suggest that the evaluation of PLS3 concentration in plasma samples may be used as a cancer diagnostic marker, predictor of sensitivity to nivolumab and a marker of poor prognosis for patients with NSCLC. Future prospective studies are required to confirm these results and explore the use of PLS3 as a marker in other types of cancer.

\section{Acknowledgements}

The authors would like to thank Ms. Mariko Nakamura, Ms. Yukie Saito, Ms. Sayaka Okada, Ms. Kayoko Takahashi, Ms. Mizuho Murata, Ms. Harumi Kanai, Ms. Fumie Takada, Ms. Yukiko Suto and Ms. Sawa Nagayama (Department of General Surgical Science, Graduate School of Medicine, Gunma University, Gunma, Japan) for their assistance.

\section{Funding}

This study was supported by Grants-in-Aid for Scientific Research from the Japanese Society for the Promotion of Science (grant nos. 17K19893 and 18K07665). The work was also supported in part by the Research Grant of the Princess Takamatsu Cancer Research Fund (grant no. 18-25034) and Suzuken Memorial Foundation.

\section{Availability of data and materials}

The datasets used and or/analyzed during the current study are available from the corresponding author on reasonable request.

\section{Authors' contributions}

TYo designed the study and wrote the initial draft of the manuscript. TYo, KS and HS contributed to data analysis and interpretation and assisted in the preparation of the manuscript. KKu, MS, NN, TYa, IN, HK and KKa contributed to data collection and interpretation, critically reviewed the manuscript. All authors read and approved the final manuscript.

\section{Ethics approval and consent to participate}

This study conformed to the Declaration of Helsinki and was approved by the Institutional Review Board for Clinical Research at the Gunma University Hospital (Maebashi, Japan; approval nos. 1404, 150044 and HS2019-271). Informed consent was obtained from the participants included in the study.

\section{Patient consent for publication}

Not applicable.

\section{Competing interests}

Kyoichi Kaira has received research grants and a speaker honorarium from Ono Pharmaceutical Company, Boehringer Ingelheim, Chugai Pharmaceutical, Taiho Pharmaceutical, Eli Lilly Japan and AstraZeneca. Department of Innovative Cancer Immunotherapy, Gunma University is an endowment department, supported with an unrestricted grant from Ono Pharmaceutical Company, Chugai Pharmaceutical Company and Memolead Company. The other authors declare that they have no competing interests.

\section{References}

1. Bray F, Ferlay J, Soerjomataram I, Siegel RL, Torre LA and Jemal A: Global cancer statistics 2018: GLOBOCAN estimates of incidence and mortality worldwide for 36 cancers in 185 countries. CA Cancer J Clin 68: 394-424, 2018.

2. Planchard D, Popat S, Kerr K, Novello S, Smit EF, Faivre-Finn C, Mok TS, Reck M, Van Schil P, Hellmann MD, et al: Metastatic non-small cell lung cancer: ESMO clinical practice guidelines for diagnosis, treatment and follow-up. Ann Oncol 29 (Suppl 4): iv192-iv237, 2018.

3. Sawabata N, Miyaoka E, Asamura H, Nakanishi Y, Eguchi K, Mori M, Nomori H, Fujii Y, Okumura M and Yokoi K; Japanese Joint Committee for Lung Cancer Registration: Japanese lung cancer registry study of 11,663 surgical cases in 2004: Demographic and prognosis changes over decade. J Thorac Oncol 6: 1229-1235, 2011.

4. Akamatsu H, Ninomiya K, Kenmotsu H, Morise M, Daga H, Goto Y, Kozuki T, Miura S, Sasaki T, Tamiya A, et al: The Japanese lung cancer society guideline for non-small cell lung cancer, stage IV. Int J Clin Oncol 24: 731-770, 2019.

5. Siegel RL, Miller KD and Jemal A: Cancer statistics, 2017. CA Cancer J Clin 67: 7-30, 2017.

6. Brahmer J, Reckamp KL, Baas P, Crinò L, Eberhardt WEE, Poddubskaya E, Antonia S, Pluzanski A, Vokes EE, Holgado E, et al: Nivolumab versus docetaxel in advanced squamous-cell non-small-cell lung cancer. N Engl J Med 373: 123-135, 2015.

7. Borghaei H, Paz-Ares L, Horn L, Spigel DR, Steins M, Ready NE, Chow LQ, Vokes EE, Felip E, Holgado E, et al: Nivolumab versus docetaxel in advanced nonsquamous non-small-cell lung cancer. N Engl J Med 373: 1627-1639, 2015.

8. Shields BD, Mahmoud F, Taylor EM, Byrum SD, Sengupta D, Koss B, Baldini G, Ransom S, Cline K, Mackintosh SG, et al: Indicators of responsiveness to immune checkpoint inhibitors. Sci Rep 7: 807, 2017.

9. Kurman JS and Murgu SD: Hyperprogressive disease in patients with non-small cell lung cancer on immunotherapy. J Thorac Dis 10: 1124-1128, 2018. 
10. Garon EB, Rizvi NA, Hui R, Leighl N, Balmanoukian AS, Eder JP, Patnaik A, Aggarwal C, Gubens M, Horn L, et al: Pembrolizumab for the treatment of non-small-cell lung cancer. N Engl J Med 372: 2018-2028, 2015.

11. Hellmann MD, Ciuleanu TE, Pluzanski A, Lee JS, Otterson GA, Audigier-Valette C, Minenza E, Linardou H, Burgers S, Salman P, et al: Nivolumab plus ipilimumab in lung cancer with a high tumor mutational burden. N Engl J Med 378: 2093-2104, 2018.

12. Fehrenbacher L, Spira A, Ballinger M, Kowanetz M, Vansteenkiste J, Mazieres J, Park K, Smith D, Artal-Cortes A, Lewanski C, et al: Atezolizumab versus docetaxel for patients with previously treated non-small-cell lung cancer (POPLAR): A multicentre, open-label, phase 2 randomised controlled trial. Lancet 387: 1837-1846, 2016.

13. Sade-Feldman M, Jiao YJ, Chen JH, Rooney MS, Barzily-Rokni M, Eliane JP, Bjorgaard SL, Hammond MR, Vitzthum H, Blackmon SM, et al: Resistance to checkpoint blockade therapy through inactivation of antigen presentation. Nat Commun 8: 1136, 2017.

14. McGranahan N, Rosenthal R, Hiley CT, Rowan AJ, Watkins TBK, Wilson GA, Birkbak NJ, Veeriah S, Ven Loo P, Herrero J, et al: Allele-specific HLA loss and immune escape in lung cancer evolution. Cell 171: 1259-1271.e11, 2017.

15. Pitt JM, Vetizou M, Daillere R, Roberti MP, Yamazaki T, Routy B, Lepage P, Boneca IG, Chamaillard M, Kroemer G and Zitvogel L: Resistance mechanisms to immune-checkpoint blockade in cancer: Tumor-intrinsic and -extrinsic factors. Immunity 44: 1255-1269, 2016.

16. O'Donnell JS, Long GV, Scolyer RA, Teng MW and Smyth MJ: Resistance to PD1/PDL1 checkpoint inhibition. Cancer Treat Rev 52: 71-81, 2017.

17. Polyak K and Weinberg RA: Transitions between epithelial and mesenchymal states: Acquisition of malignant and stem cell traits. Nat Rev Cancer 9: 265-273, 2009.

18. Chen L, Gibbons DL, Goswami S, Cortez MA, Ahn YH, Byers LA, Zhang X, Yi X, Dwyer D, Lin W, et al: Metastasis is regulated via microRNA-200/ZEB1 axis control of tumour cell PD-L1 expression and intratumoral immunosuppression. Nat Commun 5: 5241, 2014.

19. Loi S, Dushyanthen S, Beavis PA, Salgado R, Denkert C, Savas P, Combs S, Rimm DL, Giltnane JM, Estrada MV, et al: RAS/MAPK Activation is associated with reduced tumor-infiltrating lymphocytes in triple-negative breast cancer: Therapeutic cooperation between MEK and PD-1/PD-L1 immune checkpoint inhibitors. Clin Cancer Res 22: 1499-1509, 2016.

20. Soundararajan R, Fradette JJ, Konen JM, Moulder S Zhang X, Gibbons DL, Varadarajan N, Wistuba II, Tripathy D, Bernatchez $\mathrm{C}$, et al: Targeting the interplay between epithelial-to-mesenchymal-transition and the immune system for effective immunotherapy. Cancers (Basel) 11: 714, 2019.

21. Su MW, Dorocicz I, Dragowska WH, Ho V, Li G, Voss N, Gascoyne R and Zhou Y: Aberrant expression of T-plastin in sezary cells. Cancer Res 63: 7122-7127, 2003.
22. Giganti A, Plastino J, Janji B, Van Troys M, Lentz D, Ampe C, Sykes $\mathrm{C}$ and Friederichet $\mathrm{E}$ : Actin-filament cross-linking protein T-plastin increases Arp2/3-mediated actin-based movement. J Cell Sci 118: 1255-1265, 2005.

23. Yokobori T, Iinuma H, Shimamura T, Imoto S, Sugimachi K, Ishii H, Iwatsuki M, Ota D, Ohkuma M, Iwaya T, et al: Plastin3 is a novel marker for circulating tumor cells undergoing the epithelial-mesenchymal transition and is associated with colorectal cancer prognosis. Cancer Res 73: 2059-2069, 2013.

24. Kaira K, Higuchi T, Naruse I, Arisaka Y, Tokue A, Altan B, Suda S, Mogi A, Shimizu K, Sunaga N, et al: Metabolic activity by ${ }^{18} \mathrm{~F}$-FDG-PET/CT is predictive of early response after nivolumab in previously treated NSCLC. Eur J Nucl Med Mol Imaging 45: 56-66, 2018.

25. Eisenhauer EA, Therasse P, Bogaerts J, Schwartz LH, Sargent D, Ford R, Dancey J, Arbuck S, Gwyther S, Mooney M, et al: New response evaluation criteria in solid tumors: Revised RECIST guideline (version 1.1). Eur J Cancer 45: 228-247, 2009.

26. Kurashige J, Yokobori T, Mima K, Sawada G, Takahashi Y, Ueo H, Takano Y, Matsumura T, Uchi R, Eguchi H, et al: Plastin3 is associated with epithelial-mesenchymal transition and poor prognosis in gastric cancer. Oncol Lett 17: 2393-2399, 2019.

27. Vargas AJ and Harris CC: Biomarker development in the precision medicine era: Lung cancer as a case study. Nat Rev Cancer 16: 525-537, 2016.

28. Grunnet $M$ and Sorensen JB: Carcinoembryonic antigen (CEA) as tumor marker in lung cancer. Lung Cancer 76: 138-143, 2012.

29. De Stefano F, Chacon E, Turcios L, Marti F and Gedaly R: Novel biomarkers in hepatocellular carcinoma. Dig Liver Dis 50: $1115-1123,2018$.

30. Shimada H, Noie T, Ohashi M, Oba K and Takahashi Y: Clinical significance of serum tumor markers for gastric cancer: A systematic review of literature by the task force of the Japanese gastric cancer association. Gastric Cancer 17: 26-33, 2014.

31. Shrestha R, Prithviraj P, Anaka M, Bridle KR, Crawford DHG, Dhungel B, Steel JC and Jayachandran A: Monitoring immune checkpoint regulators as predictive biomarkers in hepatocellular carcinoma. Front Oncol 8: 269, 2018.

32. Dodagatta-Marri E, Meyer DS, Reeves MQ, Paniagua R, To MD, Binnewies M, Broz ML, Mori $\mathrm{H}$, Wu D, Adoumie M, et al: $\alpha$-PD-1 therapy elevates Treg/Th balance and increases tumor cell pSmad3 that are both targeted by $\alpha$-TGF $\beta$ antibody to promote durable rejection and immunity in squamous cell carcinomas. J Immunother Cancer 7: 62, 2019.

33. Sugimachi K, Yokobori T, Iinuma $H$, Ueda $M$, Ueo $H$, Shinden Y, Eguchi H, Sudo T, Suzuki A, Maehara Y, et al: Aberrant expression of plastin-3 via copy number gain induces the epithelial-mesenchymal transition in circulating colorectal cancer cells. Ann Surg Oncol 21: 3680-3690, 2014.

34. Ueo H, Sugimachi K, Gorges TM, Bartkowiak K, Yokobori T, Müller V, Shinden Y, Ueda M, Ueo H, Mori M, et al: Circulating tumour cell-derived plastin3 is a novel marker for predicting long-term prognosis in patients with breast cancer. $\mathrm{Br} \mathrm{J}$ Cancer 112: 1519-1526, 2015. 